\title{
Electrochemical Activity of Dendrimer-Stabilized Tin Nanoparticles for Lithium Alloying Reactions
}

Rohit Bhandari, ${ }^{\dagger, \ddagger}$ Rachel M. Anderson, ${ }^{\dagger}$ Shannon Stauffer, ${ }^{\dagger, \S}$ Anthony G. Dylla, ${ }^{\dagger, \dagger}$ Graeme Henkelman, ${ }^{\dagger, \S}$ Keith J. Stevenson, ${ }^{\dagger, \ddagger}$ and Richard M. Crooks $*,+$,

${ }^{\dagger}$ Department of Chemistry, ${ }^{\ddagger}$ Center for Nano- and Molecular Science and Technology, and ${ }^{\S}$ Institute for Computational and Engineering Sciences, The University of Texas at Austin, 105 E. 24th St., Stop A5300, Austin, Texas 78712-1224, United States

Supporting Information

ABSTRACT: The synthesis and characterization of $\mathrm{Sn}$ nanoparticles in organic solvents using sixth-generation dendrimers modified on their periphery with hydrophobic groups as stabilizers are reported. $\mathrm{Sn}^{2+}$ :dendrimer ratios of 147 and 225 were employed for the synthesis, corresponding to formation of $\mathrm{Sn}_{147}$ and $\mathrm{Sn}_{225}$ dendrimer-stabilized nanoparticles (DSNs). Transmission electron microscopy analysis indicated the presence of ultrasmall Sn nanoparticles having an average size of $3.0-5.0 \mathrm{~nm}$. X-ray absorption spectroscopy suggested the presence of Sn nanoparticles with only partially oxidized surfaces. Cyclic voltammetry studies of the Sn DSNs for $\mathrm{Li}$ alloying/dealloying reactions demonstrated good reversibility. Control experiments carried out in the absence of DSNs clearly indicated that these ultrasmall Sn DSNs react directly with $\mathrm{Li}$ to form $\mathrm{SnLi}$ alloys.

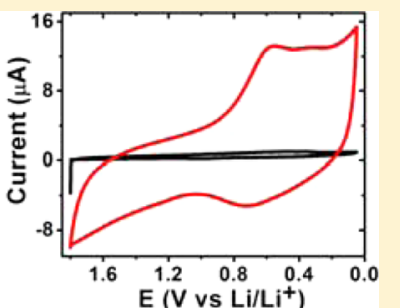

Sn DSNs

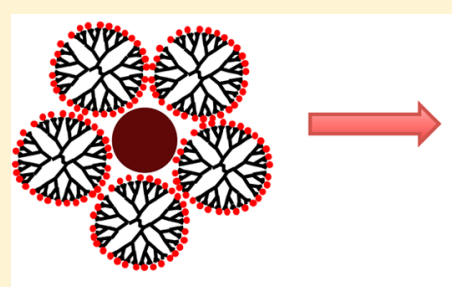

\section{INTRODUCTION}

Here, we report on a new method for synthesizing stable, ultrasmall (3-5 nm) Sn nanoparticles using poly(amidoamine) dendrimers modified on their periphery with hydrophobic groups. The resulting $\mathrm{Sn}$ nanoparticles were examined for their ability to undergo reversible electrochemical $\mathrm{Li}$ alloying and dealloying processes. There are a number of good reasons for examining the size dependence of lithium alloying and dealloying reactions for energy storage. For example, smaller particles exhibit less volume expansion during $\mathrm{Li}$ alloying reactions, ${ }^{1}$ more facile $\mathrm{Li}^{+}$transport, ${ }^{2,3}$ and diminished stressstrain relaxation properties. ${ }^{1,4}$ In addition, ultrasmall, welldefined nanomaterials can serve as models for direct comparison with first-principles theory. Accordingly, we used a well-established dendrimer-based synthesis method to prepare $\mathrm{Sn}$ nanoparticles and then evaluated their properties using electrochemical methods, electron microscopy, X-ray photoelectron spectroscopy (XPS), and X-ray absorption spectroscopy (XAS).

Over the past few years, significant research interest has been directed toward finding a replacement for the graphite anodes commonly used in Li batteries. ${ }^{5,6}$ Desirable characteristics of these replacement materials would include better stability, higher capacity, and faster charge/discharge cycling. Some of the most promising candidates are $\mathrm{Sn},{ }^{7-9} \mathrm{SnO}_{x}{ }^{10,11} \mathrm{Si},{ }^{12,13}$ $\mathrm{Ge}^{14-16}$ and $\mathrm{TiO}_{2}{ }^{17-19}$ Of these, $\mathrm{Si}$ and $\mathrm{Sn}$ are particularly promising because of their high theoretical capacity (4200 and $993 \mathrm{mAhg}^{-1}$, respectively $)^{2,6,20}$ and high degree of $\mathrm{Li}$ intercalation $\left(\mathrm{Li}_{x} \mathrm{Sn}\right.$, where $\left.0<x<4.4\right) .{ }^{1,21}$ However, these benefits are offset by the very large volume expansion that these materials undergo during $\mathrm{Li}$ alloying and dealloying steps
( $>360 \%$ for $\mathrm{Si}$ and $>200 \%$ for $\mathrm{Sn}$ ), which in turn leads to mechanical deactivation processes (e.g., cracking and pulverization) and ultimately poor rechargeability of secondary batteries. $^{20,22}$ Additionally, the competing irreversible formation of a solid electrolyte interphase (SEI) during the alloying of Sn with $\mathrm{Li}$ at reducing potentials leads to irreversible consumption (trapping of $\mathrm{Li}$ ) and therefore limited cycle life. ${ }^{11,23}$

One way to overcome the problem of volume expansion is to increase the surface-to-volume ratio of anode materials such as $\mathrm{Si}$ and $\mathrm{Sn}$, while facilitating facile electron and ion transport. $^{24-27}$ Accordingly, $\mathrm{Xu}$ et al. used a high-temperature aerosol spray pyrolysis method to prepare composites consisting of carbon spheres decorated with $\sim 10 \mathrm{~nm} \mathrm{Sn}$ particles. ${ }^{6}$ These materials exhibited good reversible capacity for $\mathrm{Li}$ alloying and dealloying without significant capacity loss over a period of 50 cycles. $^{6}$ In another study, Cabana and coworkers reported the synthesis of $10.0 \pm 0.2 \mathrm{~nm} \mathrm{Sn}$ nanocrystals using oleylamine as both the solvent and capping agent. ${ }^{25}$ The electrochemical properties of these materials were also investigated and found to exhibit better cyclability compared to commercially available $\mathrm{Sn}$ nanoparticles (25$150 \mathrm{~nm}) .{ }^{25}$ A number of related reports, ${ }^{4,8,25}$ all illustrating the advantages of ultrasmall nanoparticles of $\mathrm{Sn}(5-20 \mathrm{~nm}$ ) (and in some cases $\mathrm{SnO}_{x}$ resulting from environmental surface oxidation), ${ }^{2,28}$ have also been reported. However, to our knowledge there have been only a few examples of the study of ultrasmall, unsupported $\mathrm{Sn}$ nanoparticles in the size range

Received: April 15, 2015

Revised: May 24, 2015

Published: June 3, 2015 
below $5.0 \mathrm{~nm}$. In one such study, Deivaraj and co-workers prepared 3.5 and $10 \mathrm{~nm}$ Sn nanoparticles using 1,10phenanthroline as a chelating agent. They found that the smaller sized Sn nanoparticles demonstrated a significant improvement in cyclability during electrochemical alloying/ dealloying. $^{29}$

We and others have previously used a dendrimer-templating method to synthesize well-defined metal, metal oxide, and semiconductor nanoparticles. Collectively, these materials are known as dendrimer-encapsulated nanoparticles (DENs) ${ }^{30-32}$ Since it was first introduced by our group in $1998,{ }^{33}$ the technique of dendrimer templating has proven to be a versatile means for synthesizing nanoparticles having well-defined sizes, compositions, and structures. The basic approach for synthesizing DENs is composed of two steps. First, appropriate metal ions are mixed with a dendrimer solution. This results in encapsulation of the metal ions within the dendrimer. Second, a chemical reducing agent is added to this solution, resulting in the formation of DENs. The synthesis is usually carried out in water, but we have also shown that DENs can be synthesized in nonaqueous solvents if the surface of the dendrimer is modified with hydrophobic functional groups. ${ }^{34,35}$ Here, we used this latter approach for the synthesis of $S n$ nanoparticles to minimize oxidation of their surfaces. As we will discuss later, however, chemical interactions between the $\mathrm{Sn}^{2+}$ precursor ions and interior functional groups of the dendrimer are weak. Therefore, the materials described here are better described, and referred to hereafter, as dendrimer-stabilized nanoparticles (DSNs). Previously, we have defined DSNs as nanoparticles in the $2-5 \mathrm{~nm}$ size range surrounded by multiple dendrimers and having narrow size distributions. ${ }^{36}$

In this article we report the synthesis of ultrasmall Sn DSNs, their physical and chemical characteristics, and their electrochemical properties toward $\mathrm{Li}$ alloying and dealloying. Specifically, 3.0-5.0 $\mathrm{nm} \mathrm{Sn}$ nanoparticles were synthesized using dodecyl-functionalized hydrophobic dendrimers (G6$\mathrm{C}_{12}$ ) under an inert atmosphere in an organic solvent. The Sn nanoparticles were then characterized using UV-vis spectroscopy, transmission electron microscopy (TEM), and X-ray absorption spectroscopy (XAS). The XAS results suggest the formation of partially oxidized Sn nanoparticles. The Sn DSNs were then employed as active anode/electrode materials for studying lithium alloying/dealloying reactions.

\section{EXPERIMENTAL SECTION}

Chemicals. Sixth-generation amine-terminated poly(amidoamine) (PAMAM) dendrimers, modified on their periphery with dodecyl functional groups $\left(\mathrm{G} 6-\mathrm{C}_{12}\right)$, were purchased from Dendritech, Inc. (Midland, MI), as a $6.22 \mathrm{wt} \%$ solution in methanol/toluene. In these materials, $50 \%$ of the peripheral hydrogen atoms are substituted with the dodecyl functionality. Tin(II) trifluoromethanesulfonate (97.0\%) and $\mathrm{NaBH}_{4}$ were purchased from Sigma-Aldrich. Anhydrous solvents, including toluene, tetrahydrofuran (THF), and methanol, were also purchased from Sigma-Aldrich. All air-sensitive reagents, solvents, and stock solutions were kept inside a $\mathrm{N}_{2}$-purged M-Braun Labmaster 100 glovebox to minimize exposure to $\mathrm{O}_{2}$ and $\mathrm{H}_{2} \mathrm{O}$.

Synthesis of Sn DSNs. The commercial G6- $\mathrm{C}_{12}$ dendrimer solution was vacuum-dried to remove the solvent, and then the dendrimers were taken up in toluene to yield a $200 \mu \mathrm{M}$ stock solution. The $\mathrm{Sn}_{147}$ DSNs were prepared by mixing $300.0 \mu \mathrm{L}$ of this stock solution with $882.0 \mu \mathrm{L}$ of a $0.01 \mathrm{M} \mathrm{Sn}(\mathrm{II})$ trifluoromethanesulfonate solution (in THF). This solution was allowed to stir for $60 \mathrm{~min}$, and then a 5-fold excess of $1.0 \mathrm{M} \mathrm{NaBH}_{4}$ (dissolved in anhydrous methanol) was added to obtain zerovalent Sn DSNs: G6-C $\mathrm{C}_{12}\left(\mathrm{Sn}_{147}\right)$. A similar procedure was used for the synthesis of $\mathrm{G} 6-\mathrm{C}_{12}\left(\mathrm{Sn}_{225}\right) \mathrm{DSN}$, where $1.35 \mathrm{~mL}$ of $\mathrm{Sn}$ (II) trifluoromethanesulfonate was used to achieve the appropriate $\mathrm{Sn}^{2+}: \mathrm{G}-\mathrm{C}_{12}$ ratio.

UV-vis and TEM Characterization. UV-vis absorption spectra were collected using a Hewlett-Packard HP 8453 spectrometer and cuvettes having a path length $5.00 \mathrm{~mm}$. A $200 \mu \mathrm{M}$ G6- $\mathrm{C}_{12}$ dendrimer solution in toluene was used for background subtraction. The samples were prepared under a $\mathrm{N}_{2}$ atmosphere inside the glovebox and sealed tightly before spectral analysis. TEM analyses were conducted using a JEOL 2010F TEM operating at $200 \mathrm{keV}$. The TEM samples were prepared inside the $\mathrm{N}_{2}$ glovebox by placing a $5.00 \mu \mathrm{L}$ aliquot of the $\mathrm{Sn}$ DSNs solution on a carbon-coated copper grid, followed by overnight drying. The samples were sealed inside a TEM grid box and were exposed to air for $<2$ min during transfer to the TEM.

X-ray Absorption Spectroscopy (XAS). XAS data were collected at beamline $\mathrm{X} 18 \mathrm{~B}$ at the National Synchrotron Light Source at Brookhaven National Laboratory. $\mathrm{Sn}_{147}$ and $\mathrm{Sn}_{225}$ DSNs were prepared at a concentration of $20.0 \mu \mathrm{M}$ inside the $\mathrm{N}_{2}$ glovebox and sealed with Kapton film in a Teflon cell before removal from the glovebox. The Sn $K$ edge was analyzed, and the data were collected in fluorescence mode using a passivated implanted planar silicon (PIPS) detector. Reference samples were collected in transmission mode.

Electrochemical Analysis. All electrochemical experiments were performed using a $\mathrm{Li}$ half-cell apparatus in a three-electrode configuration with $\mathrm{Li}$ foil as both the counter and reference electrodes. Composite materials, consisting of Sn DSNs, Vulcan carbon (VC), and poly(vinylidine fluoride) (PVDF), as well as unadulterated Sn DSNs, were used as the active materials for the working electrode. A 1:1 ethylene carbonate (EC):diethylene carbonate (DEC) solution containing 1.0 M LiPF 6 was used as the electrolyte. A CHI potentiostat and an autolab potentiostat/galvanostat were used for conducting the cyclic voltammetry $(\mathrm{CV})$ experiments. The Sn DSNcontaining composite electrodes were prepared by mixing either $\mathrm{Sn}_{147}$ or $\mathrm{Sn}_{225}$ DSNs with Vulcan carbon and PVDF in the ratio of 44:28:28, respectively. The resulting slurry was drop-cast onto a clean $\mathrm{Cu}$ foil and allowed to dry for $24 \mathrm{~h}$. The unadulterated Sn DSNs were dropcast directly onto the $\mathrm{Cu}$ foil and dried for $24 \mathrm{~h}$ before electrochemical analysis. For electrochemical characterization, $\mathrm{CVs}$ were recorded in $1.0 \mathrm{M} \mathrm{LiPF}_{6} / \mathrm{EC}-\mathrm{DEC}(1: 1)$ between 1.80 and $0.05 \mathrm{~V}$ (vs Li) at scan rates ranging from 0.50 to $10.0 \mathrm{mV} / \mathrm{s}$.

\section{RESULTS AND DISCUSSION}

Preparation of Sn DSNs. As discussed in detail in the Experimental Section, Sn DSNs were prepared by mixing together solutions of a $\mathrm{Sn}(\mathrm{II})$ salt (in THF) and G6-C dendrimer (in toluene) in ratios of either 147:1 or 225:1. These solutions were stirred for $60 \mathrm{~min}$ and then reduced with $1.0 \mathrm{M} \mathrm{NaBH}_{4}$ (in anhydrous methanol) with stirring for $24 \mathrm{~h}$. The resulting solution was dark brown. These reactions were conducted inside a $\mathrm{N}_{2}$-purged inert atmosphere box to limit oxidation of the Sn DSN product. Although the resulting materials are DSNs rather than DENs, we retain the nomenclature used for DENs: $\mathrm{G}^{-} \mathrm{C}_{12}\left(\mathrm{Sn}_{x}\right)$ where the value of $x(x=147$ or 225$)$ simply represents the $\mathrm{Sn}^{2+}: \mathrm{G} 6-\mathrm{C}_{12}$ ratio used to prepare the materials.

Figure la shows a featureless UV-vis absorption spectra for solutions containing $\mathrm{Sn}^{2+}$ and the $\mathrm{G}^{2}-\mathrm{C}_{12}$ dendrimer prior to reduction. The absence of spectral features is likely an indication that $\mathrm{Sn}^{2+}$ is only weakly concentrated within the dendrimers, probably due to its higher solubility in the dendrimer interior. A similar effect has been observed previously for Au DENs prepared using organic solvents. ${ }^{34}$ In contrast to the behavior observed here, specific interactions between metal ions, such as $\mathrm{Cu}^{2+}, \mathrm{Pd}^{2+}$, and $\mathrm{Pt}^{2+}$, and particular functional groups within the dendrimer, lead to characteristic charge transfer bands between 200 and $400 \mathrm{~nm}^{30,37}$

After $\mathrm{BH}_{4}^{-}$reduction (Figure $\mathrm{lb}$ ), the UV-vis spectra exhibit an increase in absorbance toward lower wavelengths. 

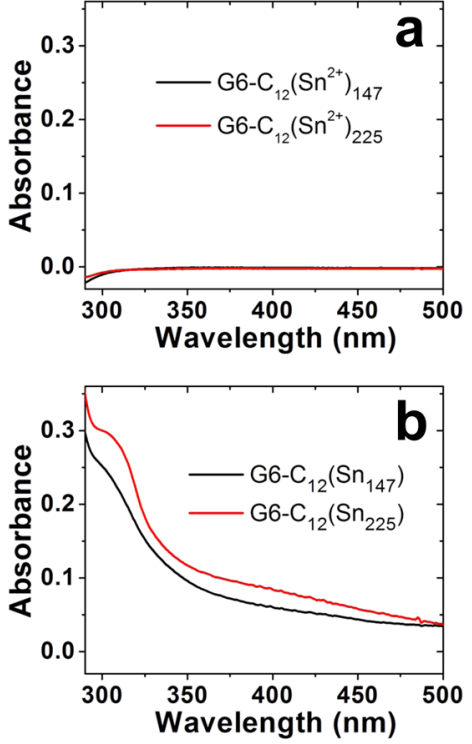

Figure 1. UV-vis absorption spectra of $2.00 \mu \mathrm{M}$ toluene solutions of (a) the Sn DSN precursors prior to reduction and (b) the Sn DSNs prepared by chemical reduction of the precursors. The solutions were sealed in a $5.0 \mathrm{~mm}$ quartz cuvette inside the drybox prior to analysis. The spectra were blanked against a $2.00 \mu \mathrm{M}$ G6- $\mathrm{C}_{12}$ solution in toluene. Note that the subscripts (147 and 225) reflect the $\mathrm{Sn}^{2+}$ :dendrimer ratio used for the synthesis and do not imply a particular number of $\mathrm{Sn}$ atoms per individual DSNs.

This is consistent with the presence of zerovalent metal nanoparticles. ${ }^{35,38}$ Note that the data shown in Figure 1 are also fully consistent with our previous report of bimetallic NiSn DENs synthesized using $\mathrm{G} 6-\mathrm{C}_{12}$ dendrimers in organic solvents. ${ }^{35}$ Importantly, control experiments conducted in the absence of the dendrimer resulted in immediate precipitation of a white solid, presumably bulk $\mathrm{Sn}$, upon addition of $\mathrm{BH}_{4}{ }^{-}$. This clearly implicates the dendrimer as a stabilizing agent, though the UV-vis data do not provide direct evidence for actual encapsulation of $\mathrm{Sn}$ nanoparticles.

TEM Analysis. Following reduction of the G6- $\mathrm{C}_{12}\left(\mathrm{Sn}^{2+}\right)_{x}$ complex with $\mathrm{NaBH}_{4}$, TEM samples were prepared inside an inert atmosphere box, dried overnight, and then transferred from the inert atmosphere box to the microscope with minimal air exposure $(<2 \mathrm{~min})$. Figure 2 presents the TEM images and particle size distributions for G6-C ${ }_{12}\left(\mathrm{Sn}_{147}\right)$ and G6-C $12\left(\mathrm{Sn}_{225}\right)$ DSNs. Because of the low atomic number of $S n$ and the small size of the particles, the quality of the micrographs is not optimal. Nevertheless, they can be analyzed, and a survey of 100 randomly selected particles yields average sizes of $3.5 \pm 0.5$ and $4.7 \pm 0.6 \mathrm{~nm}$ for the $\mathrm{Sn}_{147}$ and $\mathrm{Sn}_{225}$ DSNs, respectively. These sizes are significantly larger than would be anticipated based on the nominal number and size of $\mathrm{Sn}$ atoms present in the nanoparticles. Specifically, the calculated sizes of spherical Sn nanoparticles containing 147 and 225 atoms are 2.1 and 2.5 $\mathrm{nm}$. As mentioned in the Introduction, it is therefore likely that these materials are more accurately described as DSNs rather than DENs. DSNs form when interactions between the percursor ions $\left(\mathrm{Sn}^{2+}\right.$ in this case) and the interior groups of the dendrimer are weak (as suggested by the absence of a charge-transfer band in the UV-vis spectra).

To better define the chemical composition of the Sn DSNs, we carried out an energy dispersive X-ray (EDX) analysis. Figure $\mathrm{S} 1$ in the Supporting Information shows a typical EDX
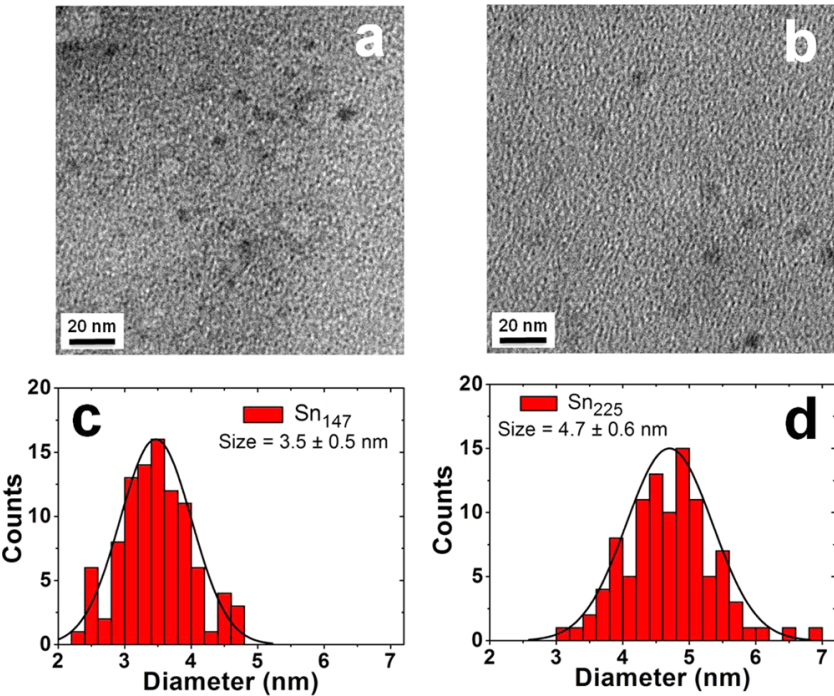

Figure 2. TEM micrographs of (a) $\mathrm{Sn}_{147}$ and (b) $\mathrm{Sn}_{225}$ DSNs. Size distribution histograms for (c) $\mathrm{Sn}_{147}$ and (d) $\mathrm{Sn}_{225}$ DSNs.

spectrum for the $\mathrm{Sn}_{225}$ DSNs in a selected area. It reveals multiple peaks corresponding to $\mathrm{Sn}(3.0-4.5 \mathrm{keV})$ as well as peaks arising from oxygen and $\mathrm{Cu}$. The oxygen signature probably arises from partial oxidation of the Sn nanoparticles during transfer into the TEM while $\mathrm{Cu}$ originates from the sample grid.

XANES and EXAFS Analysis. Figure 3 shows XANES spectra for the $\mathrm{K}$ edge of $\mathrm{Sn}_{147}$ and $\mathrm{Sn}_{225}$ DSNs as well as

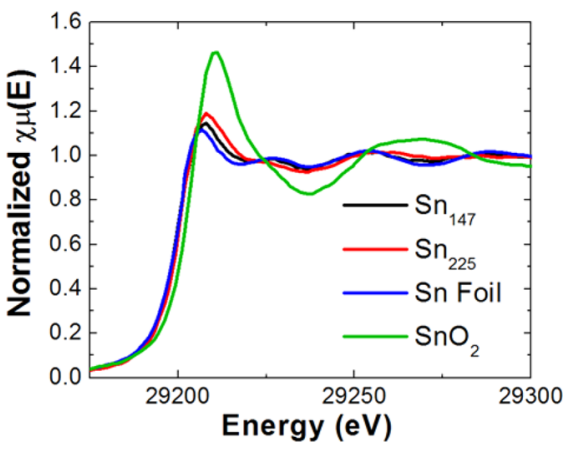

Figure 3. XANES spectra for bulk $\mathrm{Sn}$ foil and $\mathrm{SnO}_{2}$ reference materials and $\mathrm{Sn}_{147}$ and $\mathrm{Sn}_{225}$ DSNs. Comparison of the spectra reveals that the Sn DSNs most closely resemble the zerovalent $\mathrm{Sn}$ foil reference.

reference spectra for bulk $\mathrm{Sn}$ foil and bulk $\mathrm{SnO}_{2}$. Both DSN samples lack the high white line intensity present in the bulk $\mathrm{SnO}_{2}$ reference and in fact much more closely resemble the zerovalent $\mathrm{Sn}$ foil standard. This suggests that the Sn DSNs are only slightly oxidized. Moreover, analysis of individual XANES spectra indicates that partial $\mathrm{Sn}$ oxidation is at least partly due to slow air permeation into the XANES/EXAFS cell as a function of time. This can be seen in Figure S2, which shows a time-dependent increase in the white line intensity between the first and sixth scan for the $\mathrm{Sn}_{147}$ DSNs $(\sim 2.0 \mathrm{~h})$. In other words, at least some oxidation is not intrinsic to the materials, but rather an artifact of the XANES measurement. Linear combination analysis was performed on the XANES spectra shown in Figure 3 using the $\mathrm{SnO}_{2}$ and zerovalent $\mathrm{Sn}$ foil as standards. The percentages of zerovalent $\mathrm{Sn}$ were determined to be $89 \%$ for $\mathrm{Sn}_{147}$ and $77 \%$ for $\mathrm{Sn}_{225}$. The fits and further 
details regarding the analysis are presented as Supporting Information in Figure S3.

$R$-space plots of the EXAFS data and corresponding fits are shown in Figure S4, and details concerning the fits can also be found in the Supporting Information. Contributions from both $\mathrm{Sn}-\mathrm{Sn}$ and $\mathrm{Sn}-\mathrm{O}$ paths are observed in the EXAFS fits. For $\mathrm{Sn}_{225}$, the $\mathrm{CN}$ of the $\mathrm{Sn}-\mathrm{Sn}$ path $\left(\mathrm{CN}_{\mathrm{Sn}-\mathrm{Sn}}\right)$ and the $\mathrm{Sn}-\mathrm{O}$ path $\left(\mathrm{CN}_{\mathrm{Sn}-\mathrm{O}}\right)$ are $2.7 \pm 1.0$ and $1.4 \pm 0.5$, respectively. For $\mathrm{Sn}_{147}$ these values are $\mathrm{CN}_{\mathrm{Sn}-\mathrm{Sn}}=3.8 \pm 0.5$ and $\mathrm{CN}_{\mathrm{Sn}-\mathrm{O}}=0.6 \pm$ 0.3 . To determine the extent of oxidation during characterization, a numerical model was fit to the $\mathrm{CNs}$ determined experimentally by EXAFS. The details of this analysis are provided in the Supporting Information. We speculate that there is only partial oxidation in both systems due to the large contribution of first-shell $\mathrm{Sn}-\mathrm{Sn}$ interactions as compared to the $\mathrm{Sn}-\mathrm{O}$ interactions.

One final point: air was not rigorously excluded during the $\mathrm{X}$ ray analysis (the cell is somewhat air-permeable and the duration of the X-ray analysis is on the order of hours), and therefore it is certainly possible that the small amount of $\mathrm{SnO}_{2}$ observed in the X-ray analysis arises from slow air oxidation. Note that air was rigorously excluded during synthesis and during the electrochemical studies described next, so it is likely that the degree of oxidation of the Sn DSNs used for Li intercalation experiments was even lower than that determined by XANES.

Sn DSNs for the Li Alloying/Dealloying Reaction. Following characterization, the $\mathrm{Sn}_{147}$ and $\mathrm{Sn}_{225}$ DSNs were employed as active anode materials for $\mathrm{Li}$ half-cell reactions. The working electrode was prepared by drop-casting either Sn DSNs only or a composite of Sn DSNs consisting of a slurry mixture of Sn DSNs, Vulcan carbon (VC), and the PVDF binder on a $\mathrm{Cu}$ foil. The electrodes were placed in a Teflon cell inside an Ar-purged glovebox. Cyclic voltammetry (CV) experiments were then conducted at potentials between 1.8 and $0.05 \mathrm{~V}$ at scan rates ranging from 10.0 to $0.5 \mathrm{mV} / \mathrm{s}$ (Figure 4). Prior studies have shown that the alloying peaks for $\mathrm{Li}$ with Sn generally occur at potentials $<0.8 \mathrm{~V}$ and that multiple $\mathrm{Li}-\mathrm{Sn}$ phases are observed corresponding to different stoichiometries $\left(\mathrm{Li}_{x} \mathrm{Sn}\right.$, where $\left.0.0 \leq x \leq 4.4\right){ }^{4,25}$

The black CV shown in Figure 4a was obtained for a control experiment wherein the electrode was prepared with only a mixture of VC and PVDF (no Sn DSNs). The other black CVs presented in Figure 4 were obtained similarly, though the scan rates (indicated in the legends) varied. The $\mathrm{Sn}_{147}$ composite electrodes (red CVs in Figure 4a) reveal a featureless increase in current during the first two scans toward lower potentials (from 1.8 to $0.05 \mathrm{~V}$ ). We associate the fraction of this current above background (i.e., the black $\mathrm{CV}$ ) with $\mathrm{Li}$ alloying into the Sn DSNs. The reverse scans (from 0.05 to $1.8 \mathrm{~V}$ ), however, reveal a very small dealloying peak at $\sim 0.5 \mathrm{~V}$, suggesting a somewhat defined Li-dealloying step. ${ }^{4}$ A broad peak at $\sim 1.4 \mathrm{~V}$ is also observed during the reverse scan that could be assigned to either formation of the solid electrolyte interphase (SEI) or electrolyte decomposition catalyzed by the zerovalent $\mathrm{Sn}$ nanoparticles. $^{39-41}$

The red CVs in Figure $4 \mathrm{~b}$ were obtained after those in Figure $4 \mathrm{a}$ and using the same electrode; the only difference is that the scan rate was slowed from 10.0 to $0.50 \mathrm{mV} / \mathrm{s}$. The first scan toward lower potentials in Figure $4 \mathrm{~b}$ reveals significant cathodic current between 1.1 and $0.3 \mathrm{~V}$, but the current during the second scan in this potential range is much lower. During the
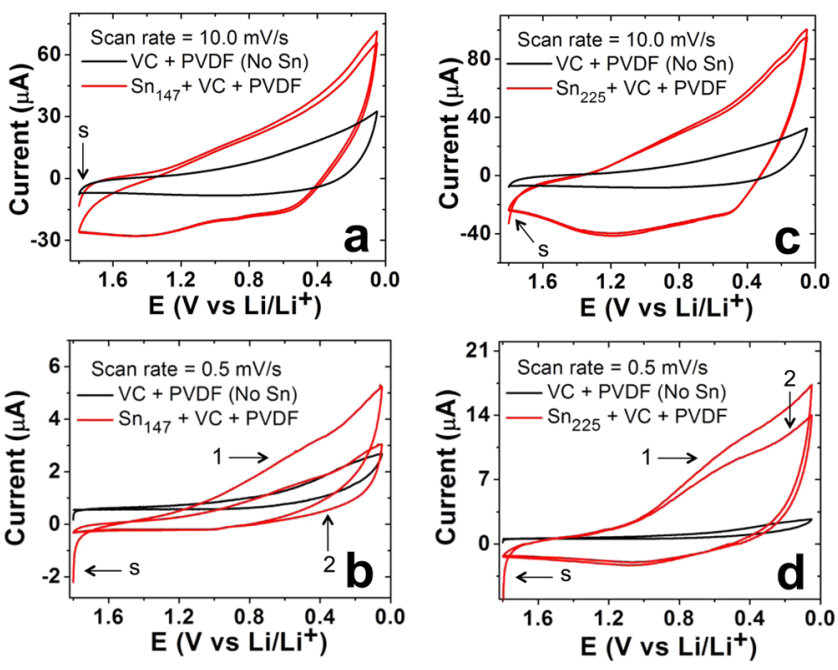

Figure 4. CVs obtained for $\mathrm{Cu}$ foil electrodes coated with (black traces) Vulcan carbon (VC) and PVDF only and (red traces) Vulcan carbon, PVDF, and Sn DSNs. (a, b) G6-C $\mathrm{C}_{12}\left(\mathrm{Sn}_{147}\right)$ DSNs and (c, d) G6- $\mathrm{C}_{12}\left(\mathrm{Sn}_{225}\right)$ DSNs. The scan range was from 1.8 to $0.05 \mathrm{~V}$. For electrodes modified with Sn DSNs, two complete scans are shown. The scan rates are indicated in the legends. The electrolyte solution contained 1.0 $\mathrm{M} \mathrm{LiPF}_{6}$ and 1:1 EC:DEC. The reference electrode was a $\mathrm{Li}$ wire. The initial potential is indicated by $\mathrm{s}$, and the numbers 1 and 2 indicate the first and second scans, respectively.

reverse scan, a very small peak is present at $\sim 1.0 \mathrm{~V}$, suggesting lithium dealloying.

The red $\mathrm{CV}$ in Figure $4 \mathrm{c}$ is equivalent to the corresponding red CV in Figure 4a, except here the DSNs are the larger $\mathrm{Sn}_{225}$ materials. The main features of this $\mathrm{CV}$ are similar to those in Figure 4a. For example, the forward scan is featureless, but because the $\mathrm{Sn}$ particles are a little bigger, the small peaks noted for the $\mathrm{Sn}_{147} \mathrm{DENs}$ at $\sim 0.5$ and $1.4 \mathrm{~V}$ on the reverse scan are more pronounced. When the scan rate is reduced to $0.50 \mathrm{mV} / \mathrm{s}$ (Figure $4 \mathrm{~d}$ ), a broad alloying peak is observed between 0.9 and $0.3 \mathrm{~V}$, and a broad dealloying peak is centered at $\sim 1.0 \mathrm{~V}$.

Taken together, we can draw the following conclusions from the data in Figure 4. First, the CVs obtained with the Sn DSNs present (red CVs) clearly exhibit larger currents than those obtained in their absence (black CVs). This indicates that $\mathrm{Li}$ is alloying and dealloying with the DSNs. Second, the forward scans are nearly featureless, suggesting the presence of multiple Li-Sn phases. ${ }^{8,42}$ It has also been reported that electrodes modified with nanoparticles tend to yield a broader electrochemical response due to their high surface area. ${ }^{25}$ Higher surface areas are also associated with more extensive electrolyte decomposition, especially at lower reducing potentials, which also tends to broaden the electrochemical response. ${ }^{25}$ Third, the poorly defined onset potential, starting near $1.2 \mathrm{~V}$, likely indicates SEI formation reactions with underlying Sn alloying reactions occurring at lower potentials. These results are consistent with previous reports of pure Sn anodes. ${ }^{43,44}$ Fourth, there is a significant decay in the alloying currents with repeated scanning, particularly at the slower scan rate. This could arise from several sources. The formation of a solid electrolyte interphase (SEI) that passivates the electrode surface could inhibit $\mathrm{Li}$ alloying and dealloying processes upon cycling. It is also possible that there is a loss of active electrode material during slow $(0.5 \mathrm{mV} / \mathrm{s})$ cycling due to electrical disconnection as particles become dislodged from their conductive carbon network via well-known volume expansion ${ }^{2}$ (or from carbon/ 
SEI degradation processes) of Sn upon Li alloying. ${ }^{45-47}$ Fifth, the percentage decrease between the first and second scans in Figures $4 \mathrm{~b}$ and $4 \mathrm{~d}$ is smaller for the larger particles, suggesting enhanced stability for the $\mathrm{Sn}_{225}$ DSNs.

To better understand the Li alloying reaction with Sn DSNs, we simplified the system by eliminating both VC and PCDF. For these experiments, represented by the CVs in Figure 5, the
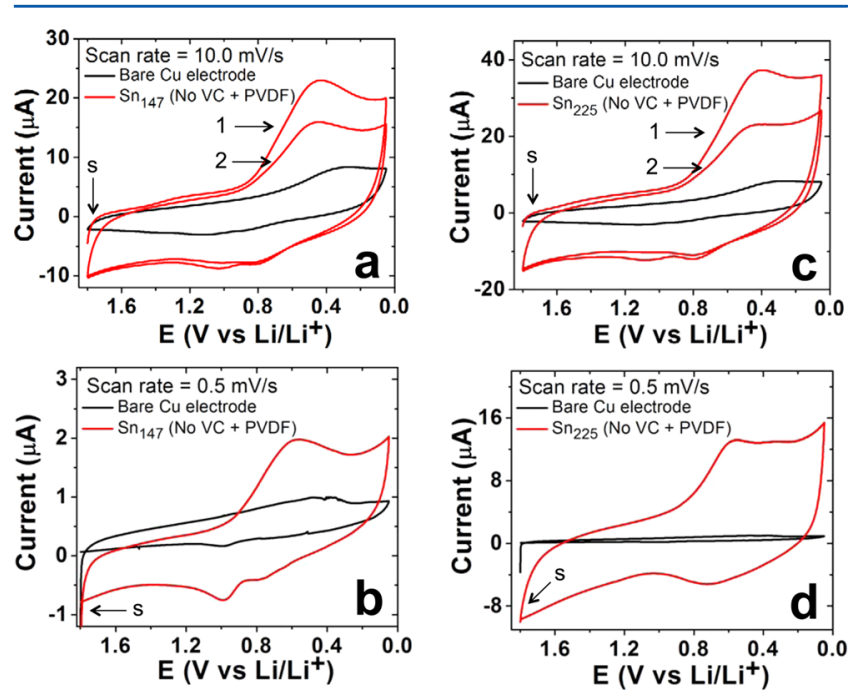

Figure 5. CVs obtained for electrodes composed of (black traces) bare $\mathrm{Cu}$ foil and (red traces) Sn DSNs physically adsorbed to the $\mathrm{Cu}$ foil (no VC or PVDF). (a, b) G6-C $\mathrm{C}_{12}\left(\mathrm{Sn}_{147}\right)$ DSNs and (c, d) G6$\mathrm{C}_{12}\left(\mathrm{Sn}_{225}\right)$ DSNs. The scans started at $1.8 \mathrm{~V}$ and ended at $0.05 \mathrm{~V}$. Two complete CVs are shown for the Sn DSN-coated electrodes at the faster scan rate. The scan rates are indicated in the legends. The electrolyte solution contained 1.0 $\mathrm{M} \mathrm{LiPF}_{6}$ and 1:1 EC:DEC. The reference electrode was a $\mathrm{Li}$ wire. The initial potential is indicated by $\mathrm{s}$, and the numbers 1 and 2 indicate the first and second scans, respectively.

working electrode was prepared using only Sn DSNs. Specifically, either $\mathrm{Sn}_{147}$ or $\mathrm{Sn}_{225}$ DSNs were drop-cast onto $\mathrm{Cu}$ electrodes and dried for $24 \mathrm{~h}$ inside the glovebox prior to the $\mathrm{CV}$ studies. The black traces presented in Figure 5 are background CVs obtained using a naked copper electrode. For example, in Figure 5a, the small peak in the black CV at $\sim 0.3 \mathrm{~V}$ may correspond to Li adsorption and SEI formation at the bare copper electrode. $^{48}$

The red CVs in Figure 5a were obtained using $\mathrm{Sn}_{147}$ DSNs and a scan rate of $10.0 \mathrm{mV} / \mathrm{s}$. The small, broad peak in the forward scan direction at $\sim 1.2 \mathrm{~V}$ can be assigned to SEI formation and the much larger peak at $\sim 0.45 \mathrm{~V}$ to $\mathrm{Li}$ alloying with the $\mathrm{Sn}_{147}$ DSNs. It has been reported that electrodeposited $\mathrm{Sn}$ on a nanostructured $\mathrm{Cu}$ current collector can form an alloy $\left(\mathrm{Cu}_{6} \mathrm{Sn}_{5}\right)$ at $\sim 0.4 \mathrm{~V}$, which can enhance $\mathrm{Li}$ alloying/dealloying with the Sn overlayer. ${ }^{45,50}$ In our study, however, we simply drop-cast the Sn DSNs onto the copper foil, and the presence of the dendrimer on the surface of $\mathrm{Sn}$ nanoparticles would likely prevent alloy formation. Hence, the peak at $\sim 0.45 \mathrm{~V}$ can be assigned to lithium alloying with Sn DSNs.

Note that the current in the second forward scan is lower than for the first, but the shape of the CV is about the same. We think this simply reflects the desorption of loosely physisorbed Sn DSNs from the copper electrode and/or subtle changes in the electroactive surface area due to volume expansion. The $\mathrm{Li}$ alloying peak at $\sim 0.45 \mathrm{~V}$ is much more distinct for electrodes modified with only Sn DSNs compared to those incorporating VC and PVDF (Figure 4a). Clearly, the presence of VC and PVDF affect the voltammetry, but whether this is due to specific chemical reactions or something more basic such as electrical resistance is not clear. What is clear is that direct support (adsorption) of Sn DSNs, without VC or PVDF on the $\mathrm{Cu}$ electrode, provides better electrochemical definition of $\mathrm{Li}$ alloying and dealloying processes.

For the reverse scan at $10.0 \mathrm{mV} / \mathrm{s}$ (Figures $5 \mathrm{a}$ ), two distinct Li dealloying peaks at $\sim 0.8$ and $\sim 1.0 \mathrm{~V}$ are observed, indicating stepwise dealloying processes from multiple $\mathrm{Li}_{x} \mathrm{Sn}$ phases. Upon changing the scan rate to $0.50 \mathrm{mV} / \mathrm{s}$ (Figure $5 \mathrm{~b}$ ), the reduction peak in the forward scan broadens and shifts slightly to a higher potential $(\sim 0.6 \mathrm{~V})$. This scan rate dependence suggests that the kinetics for $\mathrm{Li}$ alloying with $\mathrm{Sn}$ are slow, as has been observed previously for $\mathrm{Li}$ alloying with $\mathrm{Si}^{50}$ The dealloying peaks on the reverse scan are also more distinct than at the higher scan rate, consistent with kinetically slow limitations for Li dealloying.

The CV analysis of the larger $\mathrm{Sn}_{225}$ DSNs is shown in Figure $5 \mathrm{c}$,d. The results here are very similar to those obtained using the smaller DSNs with the exception of the current response being higher (consistent with the larger size of these DSNs). One significant difference is the location of the dealloying peak on the reverse scan at $0.70 \mathrm{~V}$ (Figure $5 \mathrm{~d}$ ) in comparison to 0.75 $\mathrm{V}$ (Figure $5 \mathrm{~b}$ ). The broadening and slight shift to lower potential suggest a difference in the dealloying process for different sized Sn DSNs. However, significant peak broadening during the lithium alloying/dealloying reaction is observed for both $\mathrm{Sn}_{147}$ and $\mathrm{Sn}_{225}$ DSNs as it is in other nanoscale particle electrodes. ${ }^{25}$ Hence, this idea is consistent with that observed for other shape- and size-dependent Li alloying/dealloying and $\mathrm{Li}$ conversion reactions. One final point is that only the first $\mathrm{CV}$ scan is presented in Figure 5b,d because, as alluded to earlier, the reversibility toward alloying and dealloying of the Sn DSNs (in the absence VC and PVDF) on the electrode is not sufficient to endure longer cycling periods at such slow scan rates $(0.5 \mathrm{mV} / \mathrm{s})$. Presumably, this result is a consequence of the weak interactions between the $\mathrm{Sn}$ DSNs and the $\mathrm{Cu}$ electrode surface.

Taken together, the detailed CV studies provided here suggest that the Li alloying/dealloying of ultrasmall Sn DSNs is achievable. Unfortunately, the paucity of analytical tools available for studying $\mathrm{Sn}$ nanoparticles having sizes $<5 \mathrm{~nm}$, coupled with the inherent instability of Sn nanoparticles in this size range, limits the level of mechanistic detail that we can provide at this time. Still, given the small number of publications focusing on nanoparticles in this size regime, the results provided here are a step forward toward understanding lithium alloying and dealloying reactions.

\section{SUMMARY AND CONCLUSIONS}

We successfully demonstrated the synthesis of ultrasmall $\mathrm{Sn}$ DSNs using hydrophobic $\mathrm{G}^{-} \mathrm{C}_{12}$ dendrimer in toluene and THF under inert conditions. The $S n$ materials were characterized using TEM, UV-vis, and XAS spectroscopy, and the results revealed the presence of $\mathrm{Sn}$ nanoparticles having partially oxidized surfaces. The Sn DSNs were employed as active anode materials for studying the $\mathrm{Li}$ half-cell reaction under Ar atmosphere. These CV results indicated sizedependent $\mathrm{Li}$ alloying and dealloying reactions.

Our unique methodology to synthesize these ultrasmall $\mathrm{Sn}$ DSNs using hydrophobic dendrimers, and their electrochemical 
characterization using Li half-cell reaction, could be further extended to understand size- and morphology-dependent $\mathrm{Li}$ alloying and conversion reactions for $\mathrm{Li}$-ion rechargeable batteries. Future studies will include galvanostatic experiments to determine the specific capacity of these Sn DSNs as active electrode materials, and such studies are ongoing in our laboratory.

\section{ASSOCIATED CONTENT}

\section{S Supporting Information}

EDS plot for $\mathrm{Sn}_{225}$ DSNs, comparison of the first and sixth XANES spectra, LCA fits for XANES data for $S_{147}$ and $S_{225}$ DSNs, experimental EXAFS data with fits for $\mathrm{Sn}_{147}$ and $\mathrm{Sn}_{225}$ DSNs, and the numerical model analysis. The Supporting Information is available free of charge on the ACS Publications website at DOI: 10.1021/acs.langmuir.5b01383.

\section{AUTHOR INFORMATION}

\section{Corresponding Author}

*E-mail crooks@cm.utexas.edu; Tel 512-475-8674 (R.M.C.).

\section{Notes}

The authors declare no competing financial interest.

\section{ACKNOWLEDGMENTS}

We gratefully acknowledge the Energy Frontier Research Center "Understanding Charge Separation and Transfer at Interfaces in Energy Materials (EFRC:CST)" (No. DESC0001091). R.M.C. thanks the Robert A. Welch Foundation (Grant F-0032) for sustained support. Use of the NSLS is supported by the U.S. Department of Energy, Office of Science, Office of Basic Energy Sciences, under Contract No. DE-AC02$98 \mathrm{CH} 10886$. Beamline X18B at the NSLS is supported in part by the Synchrotron Catalysis Consortium, U.S. Department of Energy Grant No. DE-FG02-05ER15688.

\section{REFERENCES}

(1) Im, H. S.; Cho, Y. J.; Lim, Y. R.; Jung, C. S.; Jang, D. M.; Park, J.; Shojaei, F.; Kang, H. S. Phase Evolution of Tin Nanocrystals in Lithium Ion Batteries. ACS Nano 2013, 7, 11103-11111.

(2) Wang, X.-L.; Feygenson, M.; Aronson, M. C.; Han, W.-Q. Sn/ SnOx Core-Shell Nanospheres: Synthesis, Anode Performance in Li Ion Batteries, and Superconductivity. J. Phys. Chem. C 2010, 114, 14697-14703.

(3) Zhu, Z.; Wang, S.; Du, J.; Jin, Q.; Zhang, T.; Cheng, F.; Chen, J. Ultrasmall Sn Nanoparticles Embedded in Nitrogen-Doped Porous Carbon As High-Performance Anode for Lithium-Ion Batteries. Nano Lett. 2013, 14, 153-157.

(4) Meduri, P.; Clark, E.; Dayalan, E.; Sumanasekera, G. U.; Sunkara, M. K. Kinetically Limited De-Lithiation Behavior of Nanoscale TinCovered Tin Oxide Nanowires. Energy Environ. Sci. 2011, 4, 16951699.

(5) Mukherjee, R.; Thomas, A. V.; Krishnamurthy, A.; Koratkar, N. Photothermally Reduced Graphene as High-Power Anodes for Lithium-Ion Batteries. ACS Nano 2012, 6, 7867-7878.

(6) Xu, Y.; Liu, Q.; Zhu, Y.; Liu, Y.; Langrock, A.; Zachariah, M. R.; Wang, C. Uniform Nano-Sn/C Composite Anodes for Lithium Ion Batteries. Nano Lett. 2013, 13, 470-474.

(7) Deng, D.; Kim, M. G.; Lee, J. Y.; Cho, J. Green Energy Storage Materials: Nanostructured $\mathrm{TiO}_{2}$ and Sn-Based Anodes for Lithium-Ion Batteries. Energy Environ. Sci. 2009, 2, 818-837.

(8) Kravchyk, K.; Protesescu, L.; Bodnarchuk, M. I.; Krumeich, F.; Yarema, M.; Walter, M.; Guntlin, C.; Kovalenko, M. V. Monodisperse and Inorganically Capped $\mathrm{Sn}$ and $\mathrm{Sn} / \mathrm{SnO}_{2}$ Nanocrystals for HighPerformance Li-Ion Battery Anodes. J. Am. Chem. Soc. 2013, 135, 4199-4202.
(9) Lian, P.; Wang, J.; Cai, D.; Liu, G.; Wang, Y.; Wang, H. Design and Synthesis of Porous Nano-Sized Sn@C/graphene Electrode Material with 3D Carbon Network for High-Performance Lithium-Ion Batteries. J. Alloys Compd. 2014, 604, 188-195.

(10) Wang, Y.; Lee, J. Y.; Zeng, H. C. Polycrystalline $\mathrm{SnO}_{2}$ Nanotubes Prepared via Infiltration Casting of Nanocrystallites and Their Electrochemical Application. Chem. Mater. 2005, 17, 38993903.

(11) Zhang, L. Q.; Liu, X. H.; Perng, Y.-C.; Cho, J.; Chang, J. P.; Mao, S. X.; Ye, Z. Z.; Huang, J. Y. Direct Observation of Sn Crystal Growth during the Lithiation and Delithiation Processes of $\mathrm{SnO}_{2}$ Nanowires. Micron 2012, 43, 1127-1133.

(12) Szczech, J. R.; Jin, S. Nanostructured Silicon for High Capacity Lithium Battery Anodes. Energy Environ. Sci. 2011, 4, 56-72.

(13) Zamfir, M. R.; Nguyen, H. T.; Moyen, E.; Lee, Y. H.; Pribat, D. Silicon Nanowires for Li-Based Battery Anodes: A Review. J. Mater. Chem. A 2013, 1, 9566-9586.

(14) Yao, C.; Wang, J.; Bao, H.; Shi, Y. Facile Synthesis of Mesoporous Ge/C Nanocomposite as Anode Material for Lithium-Ion Battery. Mater. Lett. 2014, 124, 73-76.

(15) Li, W.; Yang, Z.; Cheng, J.; Zhong, X.; Gu, L.; Yu, Y. Germanium Nanoparticles Encapsulated in Flexible Carbon Nanofibers as Self-Supported Electrodes for High Performance Lithium-Ion Batteries. Nanoscale 2014, 6, 4532-4537.

(16) Liang, W.; Yang, H.; Fan, F.; Liu, Y.; Liu, X. H.; Huang, J. Y.; Zhu, T.; Zhang, S. Tough Germanium Nanoparticles under Electrochemical Cycling. ACS Nano 2013, 7, 3427-3433.

(17) Dylla, A. G.; Xiao, P.; Henkelman, G.; Stevenson, K. J. Morphological Dependence of Lithium Insertion in Nanocrystalline $\mathrm{TiO}_{2}$ (B) Nanoparticles and Nanosheets. J. Phys. Chem. Lett. 2012, 3, 2015-2019.

(18) Froschl, T.; Hormann, U.; Kubiak, P.; Kucerova, G.; Pfanzelt, M.; Weiss, C. K.; Behm, R. J.; Husing, N.; Kaiser, U.; Landfester, K.; et al. High Surface Area Crystalline Titanium Dioxide: Potential and Limits in Electrochemical Energy Storage and Catalysis. Chem. Soc. Rev. 2012, 41, 5313-5360.

(19) Rai, A. K.; Anh, L. T.; Gim, J.; Mathew, V.; Kang, J.; Paul, B. J.; Song, J.; Kim, J. Simple Synthesis and Particle Size Effects of $\mathrm{TiO}_{2}$ Nanoparticle Anodes for Rechargeable Lithium Ion Batteries. Electrochim. Acta 2013, 90, 112-118.

(20) Kim, H.; Seo, M.; Park, M.-H.; Cho, J. A Critical Size of Silicon Nano-Anodes for Lithium Rechargeable Batteries. Angew. Chem., Int. Ed. 2010, 49, 2146-2149.

(21) Zhou, X.; Bao, J.; Dai, Z.; Guo, Y.-G. Tin Nanoparticles Impregnated in Nitrogen-Doped Graphene for Lithium-Ion Battery Anodes. J. Phys. Chem. C 2013, 117, 25367-25373.

(22) Lee, W. W.; Lee, J.-M. Novel Synthesis of High Performance Anode Materials for Lithium-Ion Batteries (LIBs). J. Mater. Chem. A 2014, 2, 1589-1626.

(23) Drozdov, A. D. Constitutive Equations for Self-Limiting Lithiation of Electrode Nanoparticles in Li-Ion Batteries. Mech. Res. Commun. 2014, 57, 67-73.

(24) Liu, Y.; Liu, X. H.; Nguyen, B.-M.; Yoo, J.; Sullivan, J. P.; Picraux, S. T.; Huang, J. Y.; Dayeh, S. A. Tailoring Lithiation Behavior by Interface and Bandgap Engineering at the Nanoscale. Nano Lett. 2013, 13, 4876-4883.

(25) Xu, L.; Kim, C.; Dong, A.; Shukla, A. K.; Mattox, T. M.; Milliron, D. J.; Cabana, J. Monodisperse Sn Nanocrystals as a Platform for the Study of Mechanical Damage during Electrochemical Reactions with Li. Nano Lett. 2013, 13, 1800-1805.

(26) Liu, X. H.; Zhong, L.; Huang, S.; Mao, S. X.; Zhu, T.; Huang, J. Y. Size-Dependent Fracture of Silicon Nanoparticles During Lithiation. ACS Nano 2012, 6, 1522-1531.

(27) Iwamura, S.; Nishihara, H.; Kyotani, T. Fast and Reversible Lithium Storage in a Wrinkled Structure Formed from Si Nanoparticles during Lithiation/Delithiation Cycling. J. Power Sources 2013, 222, 400-409.

(28) Liu, X.; Liu, F.; Sun, Q.; Ng, A. M. C.; Djurišić, A. B.; Xie, M.; Liao, C.; Shih, K.; Deng, Z. In Situ Synthesis of CuxO/SnOx@CNT 
and $\mathrm{CuxO} / \mathrm{SnOx} @ \mathrm{SnO}_{2} / \mathrm{CNT}$ Nanocomposite Anodes for Lithium Ion Batteries by a Simple Chemical Treatment Process. ACS Appl. Mater. Interfaces 2014, DOI: 10.1021/am5024308.

(29) Wang, Y.; Lee, J. Y.; Deivaraj, T. C. Tin Nanoparticle Loaded Graphite Anodes for Li-Ion Battery Applications. J. Electrochem. Soc. 2004, 151, A1804-A1809.

(30) Crooks, R. M.; Zhao, M.; Sun, L.; Chechik, V.; Yeung, L. K. Dendrimer-Encapsulated Metal Nanoparticles: Synthesis, Characterization, and Applications to Catalysis. Acc. Chem. Res. 2000, 34, 181190.

(31) Myers, V. S.; Weir, M. G.; Carino, E. V.; Yancey, D. F.; Pande, S.; Crooks, R. M. Dendrimer-Encapsulated Nanoparticles: New Synthetic and Characterization Methods and Catalytic Applications. Chem. Sci. 2011, 2, 1632-1646.

(32) Anderson, R. M.; Yancey, D. F.; Zhang, L.; Chill, S. T.; Henkelman, G.; Crooks, R. M. Theoretical and Experimental Approach for Correlating Nanoparticle Structure and Electrocatalytic Activity. Acc. Chem. Res. 2015, 48, 1351-1357.

(33) Zhao, M.; Sun, L.; Crooks, R. M. Preparation of $\mathrm{Cu}$ Nanoclusters within Dendrimer Templates. J. Am. Chem. Soc. 1998, 120, 4877-4878.

(34) Knecht, M. R.; Garcia-Martinez, J. C.; Crooks, R. M. Hydrophobic Dendrimers as Templates for $\mathrm{Au}$ Nanoparticles. Langmuir 2005, 21, 11981-11986.

(35) Gates, A. T.; Nettleton, E. G.; Myers, V. S.; Crooks, R. M. Synthesis and Characterization of NiSn Dendrimer-Encapsulated Nanoparticles. Langmuir 2010, 26, 12994-12999.

(36) Garcia, M. E.; Baker, L. A.; Crooks, R. M. Preparation and Characterization of Dendrimer-Gold Colloid Nanocomposites. Anal. Chem. 1999, 71, 256-258.

(37) Scott, R. W. J.; Wilson, O. M.; Crooks, R. M. Synthesis, Characterization, and Applications of Dendrimer-Encapsulated Nanoparticles. J. Phys. Chem. B 2005, 109, 692-704.

(38) Creighton, J. A.; Eadon, D. G. Ultraviolet-Visible Absorption Spectra of the Colloidal Metallic Elements. J. Chem. Soc., Faraday Trans. 1991, 87, 3881-3891.

(39) Lin, Y.-M.; Nagarale, R. K.; Klavetter, K. C.; Heller, A.; Mullins, C. B. $\mathrm{SnO}_{2}$ and $\mathrm{TiO}_{2}$-Supported-SnO $\mathrm{Sn}_{2}$ Lithium Battery Anodes with Improved Electrochemical Performance. J. Mater. Chem. 2012, 22, 11134-11139.

(40) Demir-Cakan, R.; Hu, Y.-S.; Antonietti, M.; Maier, J.; Titirici, M.-M. Facile One-Pot Synthesis of Mesoporous $\mathrm{SnO}_{2}$ Microspheres via Nanoparticles Assembly and Lithium Storage Properties. Chem. Mater. 2008, 20, 1227-1229.

(41) Beaulieu, L. Y.; Beattie, S. D.; Hatchard, T. D.; Dahn, J. R. The Electrochemical Reaction of Lithium with Tin Studied By In Situ AFM. J. Electrochem. Soc. 2003, 150, A419-A424.

(42) Courtney, I. A.; Dahn, J. R. Electrochemical and In Situ X-Ray Diffraction Studies of the Reaction of Lithium with Tin Oxide Composites. J. Electrochem. Soc. 1997, 144, 2045-2052.

(43) Kawamura, T.; Kimura, A.; Egashira, M.; Okada, S.; Yamaki, J.-I. Thermal Stability of Alkyl Carbonate Mixed-Solvent Electrolytes for Lithium Ion Cells. J. Power Sources 2002, 104, 260-264.

(44) Yu, Y.; Yang, Q.; Teng, D.; Yang, X.; Ryu, S. Reticular Sn Nanoparticle-Dispersed PAN-Based Carbon Nanofibers for Anode Material in Rechargeable Lithium-Ion Batteries. Electrochem. Commun. 2010, 12, 1187-1190.

(45) Shin, H.-C.; Liu, M. Three-Dimensional Porous Copper-Tin Alloy Electrodes for Rechargeable Lithium Batteries. Adv. Funct. Mater. 2005, 15, 582-586.

(46) Brousse, T.; Crosnier, O.; Devaux, X.; Fragnaud, P.; Paillard, P.; Santos-Peña, J.; Schleich, D. . Advanced Oxide and Metal Powders for Negative Electrodes in Lithium-Ion Batteries. 3rd Fr. Colloq. Powder Sci. Technol. 2002, 128, 124-130.

(47) Veeraraghavan, B.; Durairajan, A.; Haran, B.; Popov, B.; Guidotti, R. Study of Sn-Coated Graphite as Anode Material for Secondary Lithium-Ion Batteries. J. Electrochem. Soc. 2002, 149, A675A681.
(48) Paolella, A.; Brescia, R.; Prato, M.; Povia, M.; Marras, S.; De Trizio, L.; Falqui, A.; Manna, L.; George, C. Colloidal Synthesis of Cuprite $\left(\mathrm{Cu}_{2} \mathrm{O}\right)$ Octahedral Nanocrystals and Their Electrochemical Lithiation. ACS Appl. Mater. Interfaces 2013, 5, 2745-2751.

(49) Bazin, L.; Mitra, S.; Taberna, P. L.; Poizot, P.; Gressier, M.; Menu, M. J.; Barnabé, A.; Simon, P.; Tarascon, J.-M. High Rate Capability Pure Sn-Based Nano-Architectured Electrode Assembly for Rechargeable Lithium Batteries. J. Power Sources 2009, 188, 578-582.

(50) Chandrasekaran, R.; Magasinski, A.; Yushin, G.; Fuller, T. F. Analysis of Lithium Insertion/Deinsertion in a Silicon Electrode Particle at Room Temperature. J. Electrochem. Soc. 2010, 157, A1139A1151. 